revista ANTHROPOLÓGICAS

Ano 21, 28(2): 57-84, 2017

\title{
A Construção Política da Identidade em Contextos de Sobreposição de Áreas Protegidas e de Violência Contra Povos Indígenas e na Amazônia
}

Katiane Silva ${ }^{a}$

Este artigo tem como objetivo discutir o 'Caso do Buiuçu' enquanto um processo de engajamento de diversos segmentos - estatal/ ambientalista, indígena/extrativista - pela permanência de indígenas Cocama e extrativistas (oriundos da mesma família) em seu local de moradia, no Estado do Amazonas. Durante o processo de litígio os indígenas passaram por diversas situações de racismo, violência simbólica e física, resultando em sofrimentos, desgastes e o reforço das noções preconceituosas e o estigma de 'ser índio' numa região caracterizada por ataques aos diversos povos indígenas que lá residem. Por meio da análise do processo aberto pela procuradoria federal do IBAMA ( $\left.n^{\circ} 2005.32 .00 .007148-3\right)$ contra a posse irregular dos lagos disputados, das reações dos empresários (supostos donos dos lagos) ao processo, de ofícios, cartas e relatos de entrevistas procuro construir o 'Caso do Buiuçu' e demonstrar os diversos pontos de vista dos atores sociais sobre os diversos momentos e situações violentas por eles vivenciados.

Violência; Povos Indígenas; Unidades de Conservação; Racismo.

Este artigo tem como objetivo discutir o 'Caso do Buiuçu' enquanto um processo de engajamento de diversos segmentos - estatal/ ambientalista, indígena/extrativista - pela permanência de indígenas Cocama e extrativistas (oriundos da mesma família) em seu local de

a Docente na Faculdade de Ciências Sociais e no Programa de Pós-Graduação em Antropologia (PPGA-UFPA). Email: katiane.mars@gmail.com. 
moradia. A contenda ocorreu nas comunidades Santa União e Itaboca, em meados dos anos 2000, localizadas na confluência entre a Reserva Extrativista (Resex) Auati-Paraná e a Reserva de Desenvolvimento Sustentável (RDS) Mamirauá, localizadas nas regiões do Médio e do Alto Solimões, Amazonas. Durante o processo de litígio os indígenas passaram por diversas situações de racismo, violência simbólica e física, resultando em sofrimentos, desgastes e o reforço das noções preconceituosas e o estigma de 'ser índio' numa região caracterizada por ataques aos diversos povos indígenas que lá residem. Por meio da análise do processo aberto pela procuradoria federal do IBAMA ( ${ }^{\circ}$ 2005.32.00.007148-3) contra a posse irregular dos lagos disputados, das reações dos empresários (supostos donos dos lagos) ao processo, de ofícios, cartas e relatos de entrevistas procuro construir o 'Caso do Buiuçu' e demonstrar os diversos pontos de vista dos atores sociais sobre os diversos momentos e situações violentas vivenciados por eles.

A RDS Mamirauá abrange os municípios de Alvarães, Uarini, Fonte Boa e Maraã, totalizando uma área de mais de 1 milhão de hectares. Por este motivo, durante mais de dez anos foi institucionalmente dividida em: área focal (260.000 ha), onde durante muitos anos foram desenvolvidas as atividades do Projeto Mamirauá, e área subsidiária (864.000 ha), na qual essas atividades seriam desenvolvidas posteriormente. Esse modelo foi revisado pelos gestores para uma expansão e um controle mais efetivo na chamada área subsidiária e o seu atual Plano de Gestão, versão para consulta pública (IDSM, 2010), tenta incluir toda a extensão da reserva em seus programas institucionais.

A Resex Auati-Paraná é uma unidade de conservação federal, que abrange os municípios de Fonte Boa, Japurá e Maraã e possui aproximadamente uma área de 147.597.00 ha. Criada a partir do Decreto de 7 de agosto de 2001, é formada por dezesseis comunidades, ao longo do Auati-Paraná, distribuídas em sua margem direita (dentro dos limites da RDS) e esquerda (dentro dos limites da Resex). Seu conselho deliberativo foi criado por meio da Portaria 94 de 20 de 
novembro de 2008, mas somente empossado em 2009. Seu Plano de Manejo Participativo da Resex foi publicado em 2013.

As Unidades de Conservação possuem uma história específica no Rio Solimões. A proposta ambientalista não é uma iniciativa local, ela foi introduzida pela Igreja Católica, com a peculiaridade da luta por melhores condições sociais e, posteriormente, implementada pelos pesquisadores do Projeto Mamirauá, incorporando também uma orientação conservacionista. Não foram todas as comunidades que aceitaram essa proposta, mas as que aceitaram já estavam munidas com uma base do discurso do Movimento de Preservação dos Lagos, trazida pela Igreja Católica, como resistência à lógica predatória capitalista na pesca.

Nesse contexto, é importante ressaltar que o termo comunidade é recorrente na região estudada em decorrência da atuação da Igreja Católica, por meio da Prelazia de Tefé e do Movimento de Educação de Base (MEB). Durante as décadas de 1960 e 70 essas instituições promoveram programas de alfabetização popular, via a Rádio Educação Rural de Tefé, e o reordenamento territorial das famílias provenientes dos antigos seringais e de indígenas que se encontravam dispersos ao longo da calha do Rio Solimões. A ideia dos representantes da Igreja era a 'reunião' e a 'comunhão' dessas pessoas em torno de um objetivo comum: a mudança da sua condição social.

Optei pela denominação de comunitários para os membros das comunidades dispostas ao longo do Auati-Paraná, pois a história da composição desses agrupamentos sociais está extremamente marcada pelo discurso da 'comunidade cristã' das Comunidades Eclesiais de Base (CEBs). Esta autodenominação ainda tem grande difusão no local e se estende também aos indígenas. Ao perguntar aos indígenas a respeito da história do seu local de moradia, eles afirmavam que se tratava de uma comunidade indígena Cocama. A noção de comunidade também se relaciona com a de família e parente. Esses dois termos às vezes se confundem. A família se constitui como um grupo social que inclui laços de sangue, afinidade e origem comum. 
Por se tratar de uma região onde, atualmente, há recorrência de conflitos sociais oriundos dos usos dos recursos naturais, observei em diversos momentos que fazem essa configuração social faz parte de um histórico violento e as manifestações de racismo contra os povos indígenas possui uma história pregressa. Nesse sentido, uma das questões norteadoras durante a pesquisa, seja no acompanhamento dos indígenas, entrevistas ou nos arquivos que consultei, foi "como se materializa essa violência contra os povos indígenas na região estudada?". A princípio observei que essa materialização se manifestava por meio do controle territorial estatal e o modo como se marca a posse da terra e dos recursos naturais ao longo dos anos. E, como consequência, por meio também do controle das populações. Conforme foram criadas as leis, como estratégias estatais, este o controle foi se refinando e sofisticando e compondo um conjunto de regras para a permanência nos locais onde se concentram grande riqueza natural.

Dentre as diversas manifestações de violência contra os povos indígenas na região em questão, as relações de patronagem, a ideia da pacificação/domesticação do meio ambiente e o controle do comportamento das pessoas envolvidas em projetos ambientalistas corroboram a noção de uma tutela ambientalista, termo que apresentei na minha tese e que inspirada nos conceitos de tutela indigenista (Oliveira 1988) e de poder tutelar de (Lima1995), se fundamenta na ideia de que os seres humanos são obrigados a viver em harmonia entre si e com a natureza e sempre sob a guarda de um mediador externo, na figura do especialista ambiental, do pesquisador e do gestor para legitimar as intervenções políticas e administrativas. Esse processo foi possivel a partir do desenvolvimento de um 'ambientalismo-cristão', característico da região, que promoveu novos processos novos de territorialização, bem como da ação política de diversos empresários e comerciantes.

Em 2003 um grupo de empresários proibiu a entrada dos indígenas e extrativistas no 'complexo' de lagos do Buiuçu e, deste modo, configurou-se um cenário propício para a luta contra o sistema de do- 
minação concretizado na relação de patronagem, generalizado na região. Com o auxílio de juristas, os empresários construíram uma peça jurídica baseada na acusação de interesse financeiro por parte dos indígenas e contrariam e contestam a identidade indígena. Durante este exercício analítico foi possível perceber três aspectos que se destacam na construção das peças jurídicas: o primeiro é a ameaça ao poder de polícia do IBAMA; o segundo é ameaça ao pirarucu, uma espécie de peixe que já esteve em vias de extinção; e o terceiro, é o sofrimento das pessoas envolvidas na disputa pelo acesso aos lagos. Os protagonistas do conflito são invocados nas peças jurídicas como 'indígenas sofridos', mas, ao mesmo tempo, seu sofrimento é constantemente questionado e visto com desconfiança tanto pelos empresários quanto por seus familiares, que, mais tarde, os acusam de 'falsos indígenas'.

A disputa com o grupo de empresários desestabilizou as relações familiares dos envolvidos, desembocando rusgas internas e que reverberaram externamente entre as instituições mediadoras. $\mathrm{O}$ processo de luta também teve como consequência a reivindicação da criação de uma Terra Indígena na confluência dessas duas Unidades de Conservação (UC). Ocorre que as duas comunidades em conflito, Santa União e Itaboca, são formadas por membros da família Arantes, e passaram por diversos momentos de ruptura e alianças. Descendentes de indígenas Cocama de Requena, Peru, que se estabeleceram na região no final do século XIX em busca de melhores condições de vida, atualmente, os membros de Itaboca se consideram descendentes de indígenas Cocama e Cambeba, já os parentes de Santa União se auto denominam indígenas Cocama e participam ativamente do movimento indígena, formando as bases para as reivindicações de seus direitos básicos.

Os Cocama são classificados, em termos linguísticos, como pertencentes ao tronco Tupi. A língua Cocama foi se transformando durante todos esses anos de contato e há indícios de seu emprego como língua franca nas missões dos Jesuítas de Maynas, área que corresponde atualmente ao território do Departamento de Loreto (Cabral 
1995; Fabre 2005). A maioria dos estudos que tive acesso está relacionada à documentação da língua, ameaçada de desaparecimento. Estão localizados no Peru, Brasil e Colômbia, nas regiões do rio Napo, Huallaga, Putumayo (denominado Içá, no Brasil) e Solimões. No Peru, há dois subgrupos: Cocama e Cocamilla. Este último é oriundo da cisão do grupo Cocama em meados do século XVII, quando um pequeno grupo desta etnia se instalou na região do baixo Huallaga, passou a se chamar Cocamilla e, em 1853, veio a fundar a cidade de Nauta (Petesh 2003).

No Brasil, estão presentes nos municípios de Amaturá, Benjamin Constant, Santo Antônio do Içá, São Paulo de Olivença, Tabatinga, Tonantins, Tefé, Fonte Boa, Jutaí (Ministério da Saúde 2001). Também estão presentes em Manaus, em uma comunidade no ramal do Brasileirinho, bairro João Paulo, zona rural da cidade. A comunidade é composta por dez famílias, oriundas do alto e médio Solimões, em sua maioria provenientes do município de Santo Antônio do Içá (Ramalho 2008).

Várias situações conflituosas e reivindicações por criação de Terras Indígenas foram detectadas e problematizadas pelas instituições gestoras das UCs. No caso da aldeia Santa União, a reivindicação da criação de um território indígena em uma área que abrange o complexo do Buiuçu, acirrou as discussões sobre a propriedade e utilização dos recursos naturais nas comunidades e nas instituições mediadoras.

\section{A patronagem e a violência como elementos constitutivos do controle territorial}

Para alisar o contexto conflituoso local optei por trabalhar com o conceito de violência proposto por Blok (2001), cuja proposta considera a como uma categoria cultural, ou seja, como uma forma ou construção cultural, produzida historicamente e, justamente por isso, deve ser contextualizada. A violência não deve ser tomada a priori como uma ação sem sentido ou irracional dos atores sociais, mas deve ser entendida como uma ação simbólica, significativa e também concreta. Daí a importância do levantamento documental e das entrevistas que fiz na tentativa de esboçar um quadro histórico e social local, ou seja, 
no esforço de compreender o contexto no qual a violência se tornou e se torna presente.

Essa violência, contextualizada, pode ser também combinada com a ideia do potencial transformador do terror, do qual trata Michael Taussig. Para o autor, é através de uma experiência de aproximação da morte que pode surgir o "sentimento mais vívido da vida; através do medo poderá acontecer não apenas um crescimento de autoconsciência, mas igualmente a fragmentação e então a perda de autoconformismo perante a autoridade" (1993:29). Este movimento de resistência ao terror ou mesmo superação é também um dos eixos que esta tese trata. Contudo, nem todo espaço configurado no campo é de terror. Os momentos constituídos pelas desavenças familiares e as disputas pelo direito ao território caracterizam a tomada de consciência e a resistência às pressões externas. Foi a partir de uma experiência extrema, da ameaça de expulsão de seu lugar de moradia, que a família Arantes oscilou entre a (re)união e a desavença e buscou reconquistar seu lugar.

Durante a pesquisa procurei fazer o levantamento dessa espécie de 'história da violência local' a partir de relatos dos indígenas, de não indígenas e nos arquivos da Prelazia de Tefé ${ }^{1}$. Pesquisei os relatórios produzidos pela equipe da Prelazia de Tefé entre as décadas de sessenta a noventa, especificamente os relatórios de viagem dos educadores do Movimento de Educação de Base (MEB), as cartas do Padre Jean-Baptiste Parissier, um levantamento sobre os seringais produzido pelo padre Tastevin ${ }^{2}$, os relatórios de pesquisa e escritos do padre Teodoro Van Zoggel (diário, sistematização de informações de campo e entrevistas transcritas) e do então padre Egon Dionisio Heck ${ }^{3}$ (do final da década de setenta), com os quais pude comparar as representações dos envolvidos com a empresa seringalista e a pesca com as narrativas dos indígenas.

Em Fonte Boa, com ajuda de Dom Mario Clemente $\mathrm{Neto}^{4}$, tive acesso aos livros de Tombo da Paróquia de Fonte Boa e livros de batismo e casamento, com os quais elaborei um inventário da presença da família Arantes, seus casamentos, batismos, e onde pude identificar 
a relação com os patrões locais. Em Manaus, pesquisei no fundo da empresa J.G. Araújo \& Cia Ltda, sob a salvaguarda do Museu Amazônico, por meio de um acordo entre a Universidade Federal do Amazonas e a empresa, firmado em 1989, onde pude observar, por meio de correspondências, as relações entre as casas aviadoras de Manaus e do interior de Fonte Boa.

A partir da leitura e análise desses documentos procurei examinar aspectos históricos da relação de patronagem, as narrativas oficiais sobre o 'projeto colonizador' da região, constituído com base na violência, tanto física quanto simbólica. Parte dos textos que analisei revelaram as estratégias da Igreja, as relações políticas locais, situações violentas e conflitos que foram formando aquela região. Essas relações constituíram o projeto de domesticação e exploração desta parte da Amazônia e o exercício de análise passa por diversas instâncias classificatórias, corroborando com a proposta de Zambrano Escovar (2008) em sua etnografia sobre colonizadores espanhóis e indígenas colonizados, ao argumentar que a produção de saber, as classificações e sentidos produzidos sobre estes povos são inseparáveis das relações de poder.

Santa União e Itaboca estão localizadas no município de Fonte Boa (às margens do Rio Solimões), cuja gestão municipal durante os primeiros anos de 2000, considerava a região como 'a terra do manejo sustentável'. Fonte Boa já possuiu um território maior, também composto pelo que atualmente é o município de Jutaí. Trata-se de uma região caracterizada por grandes disputas político-administrativas e de exploração tanto dos recursos naturais como da força de trabalho de indígenas e de migrantes nordestinos. Enquanto a vocação do Rio Jutaí era a exploração massiva da borracha, no Auati-Paraná a principal produção era, e ainda é, a pesqueira, com destaque para a pesca de pirarucu.

Os seringais estavam localizados em áreas distantes, no Auati-Paraná e Fonte Boa à dentro (considerando também o que hoje é o mu- 
nicípio de Jutaí), nas regiões de terra-firme, obrigando os seringueiros, nos primórdios dessa exploração, a passarem os meses da seca isolados na floresta trabalhando na coleta do látex. No final do século XIX, Fonte Boa é retratada como um vilarejo simples, com locais pantanosos e povoado formado por índios e 'mestiços receptivos'. (Bates 1979; Tavares Bastos 1975). A população, segundo Tastevin, até 1880, era composta por índios "mais ou menos civilizadas, ou de mestiços de brancos e índios" (Tastevin 2008:31). Mais tarde vieram os nordestinos, trazidos pelas casas aviadoras, como por exemplo a empresa J. G. Araújo ${ }^{5}$, e se estabeleceram nas florestas do curso dos rios Juruá, Jutaí e Japurá, considerados pelo autor como locais mais fáceis para se viver, pois eram mais próximos à Manaus e as mercadorias importadas tornavam-se mais baratas e os custos de transporte das mercadorias de exportação eram menos onerados.

A situação fundiária começa a se modificar a partir da busca por seringais, em 1870, sendo explorado primeiramente o caucho e, em seguida, a borracha. Em geral, as localidades com ocorrência de seringueiras eram habitadas por indígenas, que resistiam ao domínio dos exploradores externos (Reis 1953; Teixeira 2009). Conforme as terras eram 'conquistadas' à força, eram executados os trabalhos de demarcação e requerimento do título de propriedade, baseado na Lei $n^{\circ} 1.114$, de 27 de setembro de 1860 .

Durante minha pesquisa observei que o modo como os indígenas são tratados atualmente é decorrente da relação de patronagem e do violento sistema dos barracões. Percebi a necessidade de mais estudos a respeito da história regional e do papel das elites, na figura do patrão, no desenho territorial e político do Alto Solimões. Os setores político, econômico, religioso e das relações de parentesco estavam intimamente imbricados na construção histórica de Fonte Boa.

O comércio e a relação de patronagem local foi possível a partir da disseminação do sistema de aviamento, ou seja, o adiantamento de mercadorias e instrumentos de trabalho à credito pelo patrão para o freguês, que tinha obrigação de restituir a dívida com sua 
produção. Este sistema se desenvolveu desde o período colonial e se expandiu durante o auge da exploração da borracha. Sua imagem foi marcada pelo "terror do barracão e as relações de exploração e maustratos dos trabalhadores que se embrenhavam na floresta" (Marin 2005:46). Esta relação de dominação é central no funcionamento da rede comercial da Amazônia. Sua principal característica, como será visto a seguir na fala de um entrevistado, é a privação da liberdade de ir e vir.

A patronagem, discutida por diversos autores (Silverman 1965; Wolf 2003; Shore 2006; Powell 1970; Boissevain 1966), é uma relação contratual informal entre pessoas com condição social e poder diferentes. Esta relação impõe obrigações entre as partes: a proteção e o favor de uma parte, e a lealdade da outra. A relação pode se configurar de diversas formas, no Auati-Paraná, por exemplo, identifiquei nos livros de registros paroquiais ${ }^{6}$ várias crianças batizadas e apadrinhadas por patrões como Manoel Domingos Cavalcanti e Altino Siqueira Cavalcanti.

As famílias Cavalcanti e Affonso tiveram grande influência na política e no comércio da região. Segundo relatos de alguns indígenas e registros no Arquivo J. G. Araújo ${ }^{7}$ a região do Rio Jutaí foi dominada pela família Affonso, de 1935 a 1960. O desenho territorial de Fonte Boa foi se modificando por meio da violência e da disputa pelos seringais e áreas ricas em recursos naturais. Em 1935, a família Affonso assumiu o comando total da região. Fabiano Affonso, irmão de Benjamin, é eleito prefeito de Fonte Boa, e, assim, os dois irmãos estabeleceram suas casas comerciais em pontos estratégicos do Rio Solimões, controlando a entrada e a saída tanto de pessoas quanto de mercadorias e produtos da floresta.

A figura do patrão se concretizava na expressão 'Coronel de Barranco', um termo utilizado para designar o patrão seringalista. Este termo também foi explorado pela literatura amazonense e podemos encontrá-lo em Samuel (2005), ou mesmo na obra do português Ferreira de Castro (1972). Além disso, ainda há registrado na memória 
dos comunitários e dos indígenas a ideia de um dono, um 'coronel de barranco' que domina e controla a região.

Esse controle, representado principalmente pelo sistema de aviamento, teve como consequência o encerramento dessas populações em colocações, perseguição de indígenas, como também evidencia Iglesias (2010) sobre a experiência das correrias no Acre. Em sua tese o autor aborda a questão das correrias no Acre, que eram expedições armadas promovidas pelos patrões com o objetivo de capturar os indígenas, considerados pelos patrões seringalistas e caucheiros como selvagens. Já "para os povos indígenas, as 'correrias' resultaram em massacres, na captura de mulheres e meninos e na gradual dispersão dos sobreviventes em terras firmes dos fundos dos seringais e pelas cabeceiras principais afluentes do rio Juruá" (Iglesias 2010:18).

O patrão, 'no tempo dos antigos', era considerado dono das áreas mais ricas em recursos naturais, mesmo que essa propriedade tenha sido adquirida de modo violento. Como de costume, o patrão 'convidava', conforme relatos, as pessoas de todo Auati-Paraná e de fora da região para pescar e vender pirarucu. Em geral, o patrão possuía um barracão e o monopólio do transporte e escoamento da produção e das mercadorias. No caso da pesca do pirarucu, os peixes eram salgados pelos fregueses, fornecidos ao patrão em mantas e estocados no barracão. Os compradores das mantas de pirarucu seco ${ }^{9}$ vinham de Manaus, Manacapuru e até do Peru.

A experiência no Jutaí foi diferente. Encontrei em relatos coletados pela Prelazia de Tefé ${ }^{10}$ que indicam uma diferença significativa entre o trabalho no seringal e a mobilização para a pesca de pirarucu. No caso da região do Rio Jutaí, as disputas também eram constantes, mas o costume de 'fechar os rios', e impedir o livre trânsito, era uma estratégia de captura e prisão das pessoas. No sistema de aviamento era imprescindivel a operacionalização dos fechamentos de rios, este procedimento representava a desmobilização da força de trabalho através do controle da mobilidade. A mobilidade também era fundamental para a reprodução das localidades, das estratégias de reprodu- 
ção social dos grupos domésticos, bem como do fortalecimento das relações de vizinhança.

No caso estudado, as roças não estavam localizadas próximas aos lagos, nem as estradas de seringa, castanhais e aos locais de moradia. Por isso, a mobilidade espacial é fundamental para a reprodução dos grupos sociais, por isso os patrões operavam fundamentalmente através do controle de mobilidade. A prática do fechamento de rios é comum ainda hoje, tanto entre supostos proprietários de lagos quanto entre os comunitários e indígenas. Atualmente são utilizadas cordas amarradas nas margens dos rios, de um lado a outro. Fechar o rio ou igarapé com cordas amarradas de uma margem a outra, num território alagadiço como a várzea e o igapó na Amazônia, equivale a fincar cercas e proteger uma propriedade privada, tomada à força. Um exemplo dessa prática ocorreu fortemente em 2010, os indígenas de Santa União fecharam a 'boca' do Buiuçuzinho, para impedir a entrada de barcos intruso, inclusive dos comunitários. Isso desencadeou mais uma situaçãoconflituosa entre as duas comunidades.

É importante destacar que a ressignificação da história de ocupação da família Arantes no Auati-Paraná, bem como suas relações com as famílias economicamente 'poderosas' formam um importante conjunto de narrativas para os indígenas Cocama de Santa União. Durante o trabalho de campo por diversas vezes os indígenas narraram as histórias dos seus pais e avós os fortes laços de seus antepassados com os patrões. Apesar da existência de um aparente consenso sobre uma relação de dominação violenta nos esquemas de produção baseados no aviamento, há diferentes impressões na região sobre a patronagem. Alguns moradores antigos de Santa União afirmam que o patrão recrutava pessoas para trabalharem na pesca, na extração do látex, castanha, captura de peixe-boi, quelônios, entre outros. Martiniano, indígena Cocama de Santa União que na ocasião da pesquisa residia em Fonte Boa, destacou que durante o tempo dos patrões antigos, eles nunca foram impedidos de pescar ou retirar produtos das áreas consideradas particulares, como por exemplo, no caso do Buiuçu. 


\section{O 'Caso do Buiuçu' e a tentativa de burocratização do cotidiano}

Em meados de 2003, um grupo de empresários de Manaus e Manacapuru se estabeleceu na área do 'complexo' de lagos do Buiuçu a fim de explorar os recursos naturais, com ênfase na pesquisa e na captura do pescado para comercialização. Mais tarde, a empresa Amazonas Ecopeixe Ltda. instalou em Fonte Boa uma balsa equipada com laboratório para pesquisas e aguardava a liberação para iniciar a captura dos peixes, contudo o pedido foi negado. Assim, iniciou-se uma sucessão de reuniões, audiências, liminares, decisões judiciais e ameaças contra os moradores locais, que reivindicavam o seu direito de utilização desses recursos. A partir deste momento, a vida cotidiana dos moradores de Santa União e Itaboca foi modificada pelas constantes ameaças as suas vidas e a pressão para expulsão dos indígenas e comunitários de seu lugar de moradia.

As disputas se tornaram mais efetivas a partir agosto de 2004, por ocasião de uma reunião na sede do Instituto de Desenvolvimento Sustentável de Fonte Boa (IDSFB) ${ }^{11}$, com a presença dos líderes de Santa União, Itaboca, prefeitura, polícia, IBAMA, UNI-Tefé e o representante da empresa envolvida no caso. $\mathrm{Na}$ ocasião, o líder do grupo de empresários afirmou que possuía um documento que supostamente era o título de propriedade daquelas terras, datado de 1917. O objetivo principal da empresa era a captura e pesquisa de alevinos de pirarucu em laboratório para possível exportação, além da criação desses alevinos que ao atingir $12 \mathrm{Kg}$ seriam comercializados.

Os empresários pretendiam contratar informalmente a mão-de-obra dos comunitários e indígenas para executar os trabalhos e captura de criação dos peixes. No entanto, os custos com alimentação e manutenção dos peixes seriam de responsabilidade dos contratados. O representante da empresa afirmou que pagaria cerca de $\mathrm{R} \$ 7.000,00$ por mês como salário para cada comunidade, afirmação que os presentes na reunião não levaram a sério. Todos foram contrários às colocações do representante na reunião e não houve interesse em firmar parceria. 
Mesmo contrários às atitudes dos empresários, havia a ideia de que eles eram os donos da área e os indígenas e comunitários somente os moradores ou posseiros.

A preocupação com a prova documental sobre a titularidade da área é recorrente no discurso dos envolvidos, ou seja, o poder dos documentos foi incorporado na disputa pelo território. Apesar das reuniões anteriores onde os comunitários não concordaram com as imposições do representante da empresa envolvida no litigio, os principais envolvidos na questão do conflito do Buiuçu foram convocados para uma audiência no cartório de Fonte Boa em 24 de agosto de 2005.

Esta audiência se constituiu como um marco na mudança das relações conflituosas travadas na região do Buiuçu. Neste atual modelo de territorialização caracterizado por áreas de desenvolvimento sustentável, os conflitos intensificam-se justamente entre os anos de 2003 e 2005, período no qual o conflito ultrapassou o âmbito local e atingiu os diversos trâmites da justiça, caracterizando um embate entre a Justiça e Federal e a Estadual.

Conforme o Termo de Audiência Preliminar, de 24 de agosto de 2005 (Processo n 042/2005), o juiz da Comarca de Fonte Boa, partindo do princípio que o empresário possuía o suposto título de posse da área, determinou um acordo que consistia na permissão dada pelo empresário aos Arantes para que entrassem nos lagos do 'complexo' do Buiuçu e capturassem os peixes a serem comercializados obrigatoriamente com este empresário. Cinquenta por cento dos peixes capturados seriam repassados para o empresário, e o restante divido entre os membros da família Arantes. O empresário se comprometeria também a fornecer o material necessário para a pesca do pirarucu, como redes de pesca, gelo e transporte. $\mathrm{O}$ Termo determinava ainda que o preço do pirarucu seria estabelecido pelo governo do estado e as outras espécies seriam comercializadas a preço de mercado. A quebra do acordo implicaria o pagamento de multa de $\mathrm{R} \$ 500,00$ por dia.

$\mathrm{O}$ acordo tinha como principal meta estabelecer a suposta ordem e harmonia na área em litígio: "em virtude deste acordo, as partes 
comprometem-se a cessar as hostilidades, passando a conviver com respeito e civilidade". Isto é, em nome "do respeito e da civilidade", o Termo formalizou uma relação de patronagem em juízo, fato que chamou atenção na região. A partir dessas determinações, é possível concluir que esse acordo legitima a posse do empresário, considerado ‘dono’ pela instância judiciária da Comarca de Fonte Boa. A instituição deste acordo forçado representou um marco no 'caso do Buiuçu', para os gestores da Resex Auati-Paraná.

Neste caso, destacou-se a ação engajada de diversos setores governamentais e não governamentais em defesa, principalmente, do meio ambiente, já que os empresários utilizavam os lagos de maneira irregular, conforme relatos dos entrevistados. "O Caso do Buiuçu foi uma causa abraçada por várias instituições, por isso foi bem sucedida”, conforme Miguel Arantes, ex-secretário da Associação Agroextrativista do Auati-Paraná.

Este conflito tomou a forma de inquérito e se caracterizou como uma das principais resistências na região contra a relação de dominação, instituída na região durante anos, entre os moradores locais (indígenas, ribeirinhos, comunitários seja qual for a categoria social) e os comerciantes e empresários. Após pressões de servidores do IBAMA, de representantes do movimento indígena e de outros segmentos sociais, $\mathrm{O}$ IBAMA entrou com um processo junto à AGU solicitando a anulação do acordo e a retomadas das terras para os indígenas e comunitários.

Episódios de violência são marcantes nas lembranças dos indígenas. As irmãs Vanilza, Cleta e Orlandina Arantes, relembravam o enfrentamento ocorrido na entrada do acesso aos lagos do Buiuçu, onde os 'capangas' desses empresários abordaram violentamente Joel, filho de Vanilza. Tal situação foi um marco para a atuação mais engajada de Joel no Movimento Indígena: "Foi quando nós fomo embora diretamente pra Fonte Boa pra denunciar eles. Foi aonde nós ganhemos espaço. Foi aí que nós entremos no Movimento Indígena ${ }^{12 " . ~ D e s s e ~}$ modo, os indígenas intensificaram o processo de articulação por seus direitos, buscando a orientação de diversos grupos, via relações de pa- 
rentesco e afinidade, para uma atuação mais protagonista. Eles foram orientados por Afonso Maricaua, representante da COPIJU, e, mais tarde, por André Cruz, da UNI-Tefé e que atualmente trabalha na UNIPI-MSA. Ambas as orientações foram facilitadas pelas relações de parentesco dos Arantes tanto com a família Maricaua quanto com a família Cruz.

Os advogados dos empresários solicitaram à FUNAI de Manaus uma posição e informações sobre as Terras Indígenas do município de Fonte Boa. Em resposta, o administrador substituto encaminhou um ofício contendo as informações sobre as Terras Indígenas Acapuri de Cima (demarcada) e Uati-Paraná (homologada). De posse dessas informações, os advogados argumentaram que como a suposta Terra Indígena Santa União ainda não entrou em processo de demarcação ou homologação, seus habitantes, automaticamente, não podem ser considerados indígenas. Deste modo, a construção do argumento dos advogados dos empresários está focada na relação entre identidade e terra, ou seja, são indígenas apenas aqueles que vivem em Terras Indígenas, naturalizando e cristalizando a ideia de identidade indígena, na relação com a terra. Esta noção é constantemente contestada pelos membros de Santa União, pois eles constroem uma noção de identidade baseada no engajamento, na luta e na conquista.

$\mathrm{O}$ 'Caso do Buiuçu' representou o momento em que a indignação local contra as relações de dominação: tomou a forma de inquérito, cujo objetivo principal era a retomada da autonomia e do direito ao uso dos lagos, a partir da reivindicação de uma Terra Indígena. Este processo nos remete à forma affaire, analisada por Boltanski (1993) e que ocorre sob um processo eventual apoiado no desvelamento de um sofrimento implantado no espaço público. Um evento só se caracteriza como um affaire ou uma causa a partir da existência de um infeliz/vítima, cuja defesa se constitui numa causa na qual as pessoas se engajam politicamente. Deste modo, o discurso dos indígenas sai do âmbito do sofrimento pessoal (considerado passivo por alguns atores sociais) e se desloca para uma mobilização social. 
A imposição da proibição dos indígenas e comunitários de utilização dos recursos naturais pelos empresários se transforma em causa a partir do momento em que os atores sociais, engajados na causa da proteção ambiental e em solidariedade ao sofrimento dos indígenas, fazem a denúncia junto à AGU contra a estrutura instituída pelos empresários. Neste momento, diversas narrativas surgiram a respeito da veracidade ou não da condição dos indígenas na região. No processo de constituição de uma causa há uma diferenciação entre realidade e ficção, na questão da veracidade do sofrimento ou de sua encenação. No caso do Buiuçu há mais um aspecto abordado pelos empresários, como uma estratégia de ação contrária aos moradores locais, a respeito da veracidade da condição indígena.

"O engajamento é o engajamento na ação", conforme Boltanski (1993:9), é a intenção de agir e um horizonte de ação, que também implica no envolvimento dos mediadores em parte do processo. Deste modo, o envolvimento dos servidores do IBAMA e de outros sujeitos, mediadores, engajados na ação de proteção do meio ambiente e dos indígenas implica numa espécie de empatia no processo de denúncia de injustiças.

As narrativas das peças jurídicas e as entrevistas demonstram que o principal argumento de defesa de ambos os lados se instaura num movimento de precarização da vida (Butler 2006) dos envolvido - indígenas e ribeirinhos - e onde o espectro da burocratização se manifesta numa espécie de pacificação do cotidiano. Os documentos, ou peças jurídicas, e seus efeitos podem construir marcas, enquadrar e nomear essas pessoas em polos diferentes, utilizando-se do mesmo argumento: da fragilidade, humildade e incapacidade de 'lutar' por seus direitos, exigindo a premissa de uma suposta tutela para dar continuidade ao processo. Daí a insistência dos indígenas em não se enquadrar na categoria de 'humildes sofridos', fazer resistência ao destino traçado pela história de exploração da região e transformando essa luta numa busca pela dignidade, representada pelo direito de permanecer no seu local de origem e poder reproduzir seus costumes. 
As disputas por território também se apoiam nas atribuições, sejam internas ou externas, dos membros da família Arantes. É nesse jogo que se constituem as condições de reconhecimento desses atores sociais enquanto um grupo que resiste às intervenções normativas, seja do Estado ou de um grupo rival específico. A política da normatividade atravessa essas categorias identitárias, forçando os envolvidos a escolherem um lado, respondendo às exigências sociais, criando-se 'marcos', conforme Butler (2009) para diferenciar as vidas, cujo objetivo é maximizar ou minimizar a precarização.

No recorte temporal ao qual me refiro, da chegada dos antepassados dos Arantes até os desdobramentos deste caso, trata-se de cerca de cem anos de precarização da vida, dos indígenas e da população local, seja qual for a categoria utilizada: ribeirinhos, comunitários, pescadores, povos ou populações tradicionais. Em termos de exercício analítico, desmembro o conflito do Buiuçu em dois momentos: o primeiro se refere a reunião da família contra o inimigo comum na figura dos empresários que se apossaram da área; o segundo momento caracteriza-se pela cisão da família a partir da identificação étnica dos membros de Santa União, o que caracteriza a construção política da identidade.

\section{A construção política da identidade indígena}

Após a decisão judicial em prol dos direitos indígenas e extrativistas, os conflitos tomaram uma outra dimensão. Durante um determinado período do processo, os Arantes da comunidade Itaboca aceitaram acordos paralelos com os empresários. Tal atitude dos parentes provocou indignação entre os Arantes de Santa União, originando uma quebra de acordo de manejo, bem como o rompimento de relações até meados de 2014. No clímax dessa disputa, entre 2010 e 2012, diversos representantes de instituições ambientalistas consideravam as disputas entre os Arantes como um caso de 'briga de família'. No entanto, pude perceber que não se trata apenas de um 'problema' do âmbito privado, mas que essas disputas são fomentadas tanto pela ausência de atuação (no caso da FUNAI) quanto por determinações ins- 
titucionais demasiadas (órgãos ambientalistas), que ultrapassam as vias burocráticas e representam o controle do comportamento das pessoas que vivem nessas áreas classificadas como de Uso Sustentável. O único consenso entre os diversos atores sociais é o de que os conflitos são potencializados pela 'pressão nos lagos' e pela retirada de outros recursos naturais de maneira irracional.

A pleiteada Terra Indígena Santa União caracteriza-se por um quadrilátero de terra de várzea situada à margem direita do Auati-Paraná (afluente da margem esquerda do Rio Solimões). Compreende cinco comunidades: Santa União, com uma população de cerca de 135 pessoas, dentre elas Cocama, Ticuna e Cambeba, formada por 30 casas e 29 núcleos familiares; Itaboca, que possui 5 casas e 7 núcleos familiares com cerca de 40 pessoas; Felicidade, com cerca de 4 casas e 28 pessoas, dentre elas Cocama, Tikuna e Miranha; Boca do Buiuçuzinho, com cerca de 3 casas e 22 pessoas, dentre elas Cocama e Cambeba; e a comunidade Pacu, com cerca de 26 pessoas da etnia Miranha. Esta última foi a única comunidade que não visitei.

Das comunidades citadas acima, Santa União, Felicidade e Boca do Buiuçuzinho, como possuem o laço de parentesco muito forte, trabalham em conjunto nas atividades do Movimento Indígena em prol da demarcação dessa terra. A comunidade Pacu também está incluída no processo. Já Itaboca, incluída na extensão de terra pleiteada por sua localização, mas devido aos conflitos com os parentes de Santa União se posiciona de modo contrário a esse movimento. Essa posição teve como consequência uma atitude 'linha dura', por um tempo, por parte de Santa União, orientados por André Cruz (liderança indígena de Tefé): "se Itaboca não quiser ser índio tem que sair de lá", informaram alguns indígenas de Santa União.

Atualmente, não é possível falar em invisibilidade dos indígenas Cocama. Em Santa União pude conhecer a trajetória de pessoas que foram fundamentais no processo de reivindicação de Terras Indígenas, em Fonte Boa, do início de 2000 até agora. É certo que já existem duas Terras Indígenas: Acapuri de Cima (Fonte Boa) e Uati-Paraná (Fonte 
Boa, Tonantins e Japurá), mas os Arantes estão participando ativamente do movimento desde o final da década de noventa, quando foram orientados por Afonso Maricaua, que na ocasião fazia parte da COIAMA; e mais tarde foram orientados pela COPIJU e pela extinta UNI-Tefé. Dentre as pessoas que trabalharam na organização indígena em Santa União foram Raimundo Arantes, João Arantes e Olegário Arantes.

A autonomia indígena reivindica claramente que se coloque um desafio ao monopólio do Estado soberano. A importância da luta dos povos indígenas, evidenciando seu próprio modo de fazer política e aplicar justiça, deve ser entendido como uma reação deficiências e vieses do sistema administrativo nacional democrático formal e aparato no judicial.

Para os indígenas, a expulsão dos patrões significou a recuperação de uma área em constante ameaça, ou seja, uma vitória. Isso se concretiza tanto no discurso quanto na demarcação territorial. A ausência de uma atuação mais concreta da FUNAI no Auati-Paraná tem como uma das consequências o desenvolvimento de 'estratégias de proteção e resistência' pelos indígenas. $\mathrm{O}$ caso exemplar foi uma das primeiras ações do Movimento Indígena local ao providenciar placas informando que aquela era uma área indígena, mesmo sabendo que o processo de identificação ainda não foi iniciado. Isto já causou diversos desentendimentos entre o Movimento Indígena de Tefé e os organismos ambientais. Alguns gestores relatam, com aparente indignação, que a área não é demarcada e, portanto, não se trata de Terra Indígena oficialmente. Isso gera mais discussão sobre a 'autenticidade indígena'. Contudo, os Cocama parecem acreditar numa vitória parcial, sempre divulgada, por meio de ofícios enviados constantemente aos órgãos estatais e ambientais, de modo que o enfrentamento do inimigo (qualquer um que se oponha à causa) é reforçado também burocraticamente.

Ao mesmo tempo em que Itaboca tem dificuldade em reconhecer as 'vantagens de ser índio', Santa União parece não querer facilitar um diálogo e não percebem que a polarização e a rivalidade acabam prejudicando ambos os lados, conforme um servidor FUNAI, que vê 
a base do conflito como uma questão econômica. No entanto, observo que a economia é apenas um dos aspectos como tenho apresentado até então. As disputas políticas, territoriais e de controle social estão intimamente imbricadas neste conflito e não é com a simples mediação externa que será resolvido.

O servidor da FUNAI afirmou que uma das estratégias para iniciar um trabalho de conciliação é fortalecer o envolvimento de Tomé da Cruz, indígena Cambeba, filho de André Cruz e representante da FUNAI de Tefé, para tentar mediar e 'desfazer' o conflito, 'cirando um clima' propício para a instauração do GT para identificação das demandas. Um dos motivos para a ausência do 'clima propício', para uma servidora da FUNAI, é a disseminação da fofoca e a falta de informação quanto aos direitos indígenas. Ela acredita que até eles terminarem os relatórios dos processos que estão na frente, Riozinho e São Salvador/São Gabriel, os conflitos entre Itaboca e Santa União serão sanados. Ao comparar com outros casos, ela acredita que a situação da possível Terra Indígena Santa União está tranquila, já que os indígenas tem acesso aos recursos naturais, não passam fome, não são ameaçados por agentes externos, como madeireiros, posseiros, etc.

Com efeito, é importante ressaltar o fato de que toda demarcação de Terra Indígena também é um ato de destituição de direitos territoriais de não indígenas, como no caso da rivalidade entre Santa União e Itaboca. Há a possibilidade dos desdobramentos no desentendimento entre os parentes se complexificarem quando os comunitários de Itaboca também levantaram a questão do auto reconhecimento como indígenas, como por exemplo quando eles me indagaram: "e se a gente falar que é índio, como é que fica?"

Como estratégia de convencimento dos comunitários a chegarem um consenso, os funcionários da FUNAI pretendem fazer oficinas e conversas coletivas em Santa União. Conforme forem realizando as viagens para Santo Antônio do Içá e Jutaí, de modo a agilizar o processo de São Gabriel/São Salvador e Riozinho, os funcionários da FUNAI pretendem estender a viagem à Santa União e Itaboca para 
esclarecer dúvidas e "perceber o clima das comunidades". Pretendem iniciar o trabalho indigenista fazendo reuniões em Fonte Boa, por considerarem um território neutro, assim vão tentar uma aproximação para posteriormente visitarem as comunidades.

Alguns representantes do Movimento Indígena em Fonte Boa, como o caso do China, chocam-se com os grupos ligados a André Cruz, conforme observado anteriormente. As informações as quais a FUNAI teve acesso na viagem dos servidores à Fonte Boa são as de que alguns líderes indígenas constantemente imputam ao órgão, assim como a outras instituições, envolvidas com as atividades Unidades de Conservação, uma atuação prejudicial em relação às comunidades indígenas, pois aumentam gradualmente as restrições à pesca nos lagos.

Esses líderes chegam a informar que pessoas ligadas à RDS Mamirauá tentam convencer os indígenas a não declararem sua condição indígena, pois uma futura demarcação de áreas sobrepostas implicaria no fim do apoio às comunidades indígenas por parte das instituições gestoras das Unidades de Conservação. Mas essa compreensão não é unânime nessas localidades. A percepção dos indígenas de Santa União a respeito da atuação do IDSM, principalmente com relação à mediação do conflito, vem se modificando. Há uma aproximação dos técnicos desta instituição com o intuito de conhecer e reconhecer uma área que nunca antes foi contemplada com os projetos da instituição, já que a área em litígio está localizada na antiga área subsidiária da RDS Mamirauá.

Para os indígenas entrevistados, existem dois tipos de demarcação: aquela feita pela FUNAI (oficial), caracterizada pela morosidade e exige muita paciência dos demandantes; e aquela exercida na prática, no cotidiano, pelos indígenas, quase como o estabelecimento da posse pelo usucapião. Nascer e viver num lugar há muito tempo, para os indígenas, já significa um tipo de demarcação: é a posse efetiva e comum da terra.

Um dos aspectos que merecem a nossa atenção é o fato de que a identificação étnica não é produzida de forma neutra, mas de acor- 
do com o contexto, com as disputas locais e ideologias. Esta questão Weber (1983) já havia exposto em seu capítulo sobre 'Comunidades Étnicas', onde ele mostra que a base dessa relação está na produção dos 'costumes', posto que a diferença de costumes pode alimentar o sentimento específico de honra, dignidade e pertencimento a um povo. Aqueles motivos originários do grupo, que dão sentido às diferenças, são esquecidos e os contrastes persistem como convenções.

Weber (1983) define grupos étnicos como grupos humanos que compartilham de uma crença subjetiva numa procedência comum, de tal modo que isto se torna importante para a ampliação das comunidades. Em termos de ação coletiva, este sentido de comunalidade étnica é uma forma de inclusão social: define membros, elegibilidade e acesso. Além disso, alguns 'materiais culturais' (ou recursos materiais, nos termos de Barth) em comum podem prover a base para a inclusão étnica (ou o pertencimento), tais como: linguagem, ritual, parentesco, economia, estilo de vida e divisão do trabalho.

E no caso estudado, acrescento também os saberes jurídico-administrativos. Ter acesso à terra não significa apenas possuir um bem específico, mas a possibilidade de reprodução social, cultural, política e econômica. É assumir o compromisso e o protagonismo de sua história. Deste modo, a combinação entre o sentimento de pertença a um grupo e seus interesses, sejam econômicos ou políticos, são aspectos da composição da etnicidade em questão. Num espaço onde as fronteiras foram oficial e artificialmente reconfiguradas, etnias politizadas competem por recursos e lidam com as imposições de novos modos de ser impostos pela administração estatal. A identidade Cocama em questão também pode ser entendida como uma reconstituição ideológica, cujos identificadores de referência são recriados de acordo com o fator político e o contexto situacional.

A identidade étnica e a luta desses povos estão relacionadas à tentativa de emancipação, gerando controvérsias com relação ao monopólio administrativo do Estado. Um dos pontos crucial levantados é: será que os indígenas serão capazes de gerir a área e saberão lidar 
com os códigos burocráticos? Será que o Estado deseja permitir esta emancipação? Ao tomar como base a discussão weberiana sobre o Estado enquanto uma 'empresa', é possível perceber que não há uma abertura para a autonomia. Para sobreviver, o Estado alimenta uma dependência hierárquica do trabalhador e diversos segmentos. Uma dependência baseada no fato de que os instrumentos, recursos e saberes necessários ao seu funcionamento estão concentrados em poder do empresário, e neste caso, do aparato político-administrativo.

"Por que Santa União se assinou como indígena?", questionei durante uma conversa coletiva na casa comunitária em Santa União. "Porque Mamirauá, ele só marca onde a pessoa aceitou eles. Porque Mamirauá é assim: ele vem conversando nas comunidade e aí elas aceitam criar um setor aqui e tudo mais. Aonde a comunidade aceitar ele, ele entra. Aí eles assinam tudinho, leva, faz cadastro", respondeu Olegário. Deste modo, enquanto a opção por participar de um projeto com as dimensões da RDS Mamirauá implica na adoção um status e um estilo de vida, de certo modo, imposto da comunhão com a natureza. Uma proposta exterior, de 'algo que vem de fora' e que não surgiu propriamente de uma demanda local. A opção pela criação de um território indígena implica em 'se assinar indígena' e se constitui como uma demanda interna. Mesmo com o trabalho de mobilização para reivindicação dos direitos dessa categoria sendo mediado por atores externos, do Movimento Indígena, esses atores externos possuem a mesma condição, comungam de ideais e, às vezes, compartilham de histórias de vida semelhantes e, neste caso, constituem laços de parentesco.

Numa espécie de movimento 'subversivo' de retomada territorial, frente à expansão de RDS sendo criadas no estado do Amazonas e ao conflito iminente com os parentes, os integrantes de Santa União optaram por entrar no Movimento Indígena. Basicamente, para os integrantes de Santa União, o processo de passar pra índio possui duas vias interligadas:

1. Significa estabelecer a posse de um território indígena, ou seja, transformar um território (geralmente disputado, em litígio) em 
área indígena, ou seja, patrimônio indígena como reação à precarização da vida (resgatando o conceito trabalhado no capítulo anterior), e

2. Consequentemente, significa reivindicar os direitos perante o Estado, ter o reconhecimento da legitimidade indígena frente aos órgãos competentes, como FUNAI, FUNASA, órgãos ambientalistas, entre outros.

A filiação das comunidades a uma Unidade de Conservação ou à Terra Indígena é geralmente uma consequência do contexto histórico e das negociações decorrentes da atuação do Estado e seus efeitos sociais. No caso dos Arantes e a querela com as diversas instituições envolvidas, eles já ocupam aquele espaço, antes da criação das Unidades de Conservação, onde seus ancestrais chegaram e se reproduziram. Apesar das dificuldades impostas por uma área de várzea, o determinismo físico-geográfico não possui tanta força na definição da posse e uso da terra e lugar de moradia e da demarcação das fronteiras. Estas são definidas por meio das negociações e da participação das pessoas que vivem nas comunidades, concretizada nas relações de vizinhança, reputação e no tempo de moradia no local. As fronteiras não se reduzem simplesmente às características naturais, mas são determinadas por um corpo de relações que ultrapassam esses muros naturais e estão fundados na mobilidade e na troca de informações, da reputação e alianças, seja no Movimento Indígena, seja nos segmentos ambientalistas estatais e não governamentais.

\section{Notas}

1 Está localizado no prédio da Rádio Educação Rural de Tefé e quando lá trabalhei (entre 2012 e 2014), havia passado por um processo inicial de higienização, organização e catalogação, por meio de um projeto liderado por professores e estudantes da Universidade do Estado do Amazonas.

2 Transcrito pelo padre Theodoro Van Zoggel. 
3 Atualmente atua como coordenador do Conselho Indigenista Missionário (CIMI) do Mato Grosso do Sul.

4 Da Congregação do Divino Espírito Santo, responsável pela paróquia de Nossa Senhora de Guadalupe, no município de Fonte Boa, e bispo emérito da Prelazia de Tefé.

5 O Joaquim Gonçalves de Araújo é considerado um dos mais importantes comerciantes da Amazônia Ocidental na primeira metade do século XX, por ser a maior casa aviadora do estado. Em poucos anos acumulou um capital econômico proveniente de casas comerciais, indústrias, extrativismo, seringais e fazendas de gado (Souza 2011).

6 Encontrei referencias dos livros IX ao XXI, entre os anos de 1924 a 1952.

7 O fundo da empresa J. G. Araújo foi doado ao Museu Amazônico em 1989. Mais informações, ver: http://www.museuamazonico.ufam.edu.br/index.php/historia-e-documentacao.

8 Esta é uma categoria muito utilizada por indígenas e regionais. Serve para indicar um período no qual ainda não existia esse tipo de intervenção estatal baseada na compartimentalização do espaço, como no modelo de reserva.

9 O peixe era aberto pelos pescadores, que retiravam o filé chamado de manta e o estendiam em varais expostos ao sol e ao sal até que a carne secasse. Ao secar, as mantas eram enroladas e armazenadas no barracão do patrão para serem comercializadas. 10 Resultado de diversas viagens e pesquisas feitas pelos membros da Prelazia de Tefé, dentre eles o padre Teodoro van Zogel e do então padre Egon Dionísio Heck, Antônio Caetano (do MEB da Foz do Jutaí), Honorato Alves, da paróquia de Fonte Boa. Uma delas trata-se de pesquisa financiada pela OPAN, sobre os indígenas do rio Jutaí e sua relação com os seringueiros remanescentes dos seringais deste mesmo rio. Do material coletado foi originado um relatório sobre a situação dos indígenas e seringueiros e a brochura 'O Clamor dos Seringueiros', organizado pelos dois padres a partir de depoimentos e pesquisa documental. Pude consultar esse material no Arquivo da Prelazia de Tefé, que atualmente está localizado no térreo do prédio da Radio Educação Rural de Tefé.

11 Autarquia municipal criada em 2003, no governo do prefeito Wilson Lisboa, agregando funções de secretaria de meio ambiente e de produção. Também atua em conjunto com o IBAMA na fiscalização da pesca tanto na RDS Mamirauá quanto na Resex Auati-Paraná, e com o ICMBio, na mediação do manejo comunitário.

12 Joel Ferreira Arantes, entrevista em Santa União, em 01/02/2012.

\section{Referências}

BARTH, Fredrik. 2000. O Guru, o Iniciador e Outras Variações Antropológicas. Rio de Janeiro: Contra Capa.

BATES, Henry W. 1979. Um Naturalista no Rio Amazonas. Belo Horizonte/São Paulo: Itatiaia/EDUSP. 
BOISSEVAIN, Jeremy. 1966. "Patronage in Sicily". Man, New Series, 1(1):18-33.

BOLTANSKI, Luc. 1993. La Souffrance à Distance. Morale humanitaire, médias et politique. Paris: Éditions Métailié.

BUTLER, Judith. 2006. Vida Precária. El poder del duelo y la violência. Buenos Aires: Paidós. 2009. Marcos de Guerra. Las vidas lloradas. Buenos Aires: Paidós.

CABRAL, Ana Suelly. 1995. Contact-induced Language Change in the Western Amazon: The non-genetic origin of the Kokama language. Tese de Doutorado. Pittsburg: University of Pittsburg.

FABRE, Alain. 2005. Diccionario Etnolingüístico y Guía Bibliográfica de los Pueblos Indígenas Sudamericanos. (http://butler.cc.tut.fi/ fabre/ BookInternetVersio/Alkusivu.html; acesso em 20/01/2012).

FERREIRA DE CASTRO, José Maria. 1972. A Selva. São Paulo: Verbo.

IDSM. 2010. Plano de Gestão Reserva de Desenvolvimento Sustentável Mamirauá RDSM. Vol 1. e 2 Diagnóstico e Planejamento. Tefé (Versão para consulta pública).

IGLESIAS, Marcelo P. 2010. Os Kaxinawá de Felizardo: Correrias, trabalho e civilização no Alto Juruá. Brasília: Paralelo 15.

MINISTÉRIO DA SAÚDE. 2001. Programa Saúde Indígena: etnodesenvolvimento das sociedades indígenas. Brasília: Ministério da Saúde. (http://educampoparaense.org/site/media/biblioteca/pdf/programa\%20 saude_indigena.pdf; acesso em 15/03/2010).

POWELL, John D. 1970. "Peasant Society and Clientelist Politics". The American Political Science Review, 64(2):411-425.

RAMALHO, Ana Luiza M. 2008. Construção da Agrobiodiversidade Kokama, Comunidade São Gabriel, Alto Solimões, Amazonas. Monografia de Graduação. Manaus: UFAM.

REIS, Arthur C. F. 1953. O Seringal e o Seringueiro. Rio de Janeiro: Ministério da Agricultura. Serviço de Informação Agrícola.

SAMUEl, Rogel. 2005. O Amante das Amazonas. Rio de Janeiro: Itatiaia.

SILVERMAN, Sydel. 1965. "Patronage and Community-Nation Relationships in Central Italy”. Ethnology, 4(2):172-189.

SHORE, Cris. 2006. "The Limits of Ethnography Versus the Poverty of Theory: Patron-client relations in Europe re-visited". Sites: New Series, 3(2):40-59.

TEIXEIRA, Carlos Corrêa. 2009. Servidão Humana na Selva: O aviamento e o barracão nos seringais da Amazônia. Manaus: Editora Valer, EDUA.

TASTEVIN, Constant. 2008. "A região do Solimões ou Médio-Amazonas". In FAULHABER, P. \& MONSERRAT, R. (eds.): Tastevin e a Etnografia Indígena. Coletânea de traduções de textos produzidos em Tefé (AM), pp. 13-38. Rio de Janeiro: Museu do Índio.

TAVARES BASTOS, A. C. 1975. O Vale do Amazonas: A livre navegeação do Amazonas, estatística, produções, comércio, questões fiscais do vale do Amazonas. São Paulo/Brasília: Cia Editora Nacional/INL. 
WEBER, Max. 1983. Economia y Sociedad. México: Fondo de Cultura Económica. WOLF, Eric. 2003. Antropologia e Poder. Contribuições de Eric R. Wolf. Brasília: Editora UNB.

\begin{abstract}
This article aims to discuss the 'Buiuçu Case' as a process of engagement of several segments - state / environmentalist, indigenous / extractive - for the permanence of indigenous Cocama and extractivists (from the same family) in their place of residence, Amazonas State. During the process of litigation, indigenous people went through various situations of racism, symbolic and physical violence, resulting in suffering, weariness and the reinforcement of prejudiced notions and the stigma of "being Indian' in a region characterized by attacks on the various indigenous peoples residing there. Through the analysis of the process opened by the federal prosecutor of IBAMA ( $\mathrm{n}^{\circ}$ 2005.32.00.007148-3) against the irregular possession of the disputed lakes, the reactions of the businessmen (supposed owners of the lakes) to the process, of letters, letters and interview reports I try to build the 'Buiuçu Case' and demonstrate the different points of view of the social actors about the various moments and violent situations they experienced.
\end{abstract}

Keywords: Violence; Indigenous Peoples; Protected Areas; Racism.

Recebido em outubro de 2017.

Aprovado em dezembro de 2017. 